\title{
Frequency of Type-1 Berrettini's Connection in a Neurophysiology Laboratory
}

\author{
Juan M. Duarte ${ }^{1}$ Juan I. Rolón ${ }^{1} \quad$ Alicia B. Bertotti ${ }^{1}$ \\ ${ }^{1}$ Clinical Neurophysiology Unit-Hospital Alemán, Buenos Aires, \\ República Argentina \\ J Neurosci Rural Pract 2021;12:652-655.
}

\begin{abstract}
Address for correspondence Juan M. Duarte, Clinical Neurophysiology Unit-Hospital Alemán, Buenos Aires, República Argentina (e-mail: jduarte@hospitalaleman.com).
\end{abstract}

\author{
Abstract \\ Keywords \\ - ulnar-median nerves \\ communication \\ - ulnar nerve \\ - median nerve \\ - electromyography \\ - action potentials
}

Objective This study aims to estimate the frequency of Berrettini's ulnar-median nerves communication in a neurophysiology laboratory.

Materials and Methods A total of 358 hands belonging to patients, both sexes, median age of 58 years, was studied. Antidromic sensory nerve conduction studies of the ulnar nerves, registered in digits III and IV were performed in search of the ulnarmedian communication. A Berrettini's percentage was calculated in each communication: [(amplitude SAP digit III/amplitude SAP digit IV) $\times 100$ ].

Results Ulnar-median nerves communication (Berrettini's branch) was found in 37 hands (10.95\%), with a female gender predominance. Bilaterality percentage was low (1.78\%). Most communications encountered had a Berretini's percentage between 11 and $50 \%$. Some of them exceeded $100 \%$.

Conclusions Electromyographers should routinely search for this nerve communication, especially in those patients undergoing carpal tunnel syndrome or Dupuytren's contracture surgeries.

\section{Introduction}

Electromyographic and nerve conduction studies of the upper limbs are routine procedures in clinical neurophysiology laboratories to diagnose different peripheral nerves' disorders. Several connections between the median and ulnar nerves, outside the brachial plexus, have been identified: the MartinGrüber communication, Marinacci communication, RichéCannieu communication, and Berrettini communication. The latter consists of communication of sensory fibers, most frequently between the fourth palmar digital common nerve (coming from the ulnar nerve) and the third palmar digital common nerve (coming from the median nerve). The importance of its recognition is the potential intrasurgical injury. ${ }^{1}$ Also, $16 \%$ of iatrogenic injury cases occur due to the superposition of the sensory innervation with that of the ulnar nerve or by a motor branch to the thumb's abductor brevis muscle, originating from the deep distal branch of the ulnar nerve. ${ }^{2}$ The Berrettini connection can be injured during endoscopic surgery for carpal tunnel syndrome, or secondary to the surgical release of Dupuytren's contracture. ${ }^{3,4}$ It can even be potentially injured during open surgery. ${ }^{5}$ A study that evaluated the adverse effects of median nerve release surgery by experienced surgeons, endoscopically compared with open surgery, showed that iatrogenic injury to this connection was the most frequent during the first modality. ${ }^{6}$

Anatomical studies consider it to be a standard anatomical variant, due to its high frequency. ${ }^{1}$ However, it is not frequently investigated in electrophysiological studies on a routine basis. Therefore, this work aims to determine the frequency of this communicating branch's presence through sensory conduction studies. published online September 20, 2021
DOI https://doi.org/ 10.1055/s-0041-1734005. ISSN 0976-3147.

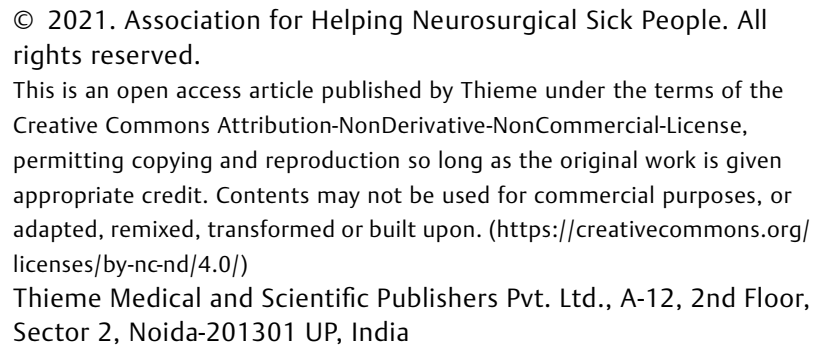

This is an open access article published by Thieme under the terms of the Creative Commons Attribution-NonDerivative-NonCommercial-License, permitting copying and reproduction so long as the original work is given appropriate credit. Contents may not be used for commercial purposes, or adapted, remixed, transformed or built upon. (https://creativecommons.org/ licenses/by-nc-nd/4.0/)

Thieme Medical and Scientific Publishers Pvt. Ltd., A-12, 2nd Floor, Sector 2, Noida-201301 UP, India 


\section{Materials and Methods}

A prospective study of the electrophysiological evaluations of the hands corresponding to patients of both sexes who attended the Clinical Neurophysiology Service of the German Hospital, Buenos Aires, Argentine Republic, during 2020. Exclusion criteria corresponded to patients with diagnoses of advanced peripheral neuropathies (acquired or hereditary), neuropathies of the ulnar nerve (at the level of the Guyon canal or the level of the ulnar canal at the elbow), those hands belonging to patients with a history of surgery for carpal tunnel syndrome, Dupuytren's contracture, or neurovascular island flaps. Patients with other neuromuscular conditions were included. Sensory conduction studies were performed antidromically, using ring electrodes on the third and fourth fingers, $4 \mathrm{~cm}$ apart (-Fig. 1). The active ring electrode was placed $1 \mathrm{~cm}$ from the base of the finger, to avoid the presence of artifacts. The temperature of the skin of the palm was kept at $32^{\circ} \mathrm{C}$. The median and ulnar nerves were stimulated, at the wrist level, at a distance of $14-\mathrm{cm}$ proximal to the active ring electrode (-Fig. 1). The averaged data of the sensory action potentials (SAP) were obtained: peak latencies and amplitudes from the baseline to the SAP obtained peak were analyzed ( - Fig. 2).

The amplitudes of the third finger's responses when stimulating the ulnar nerve were compared with the amplitudes of the responses obtained in the fourth finger when stimulating the ulnar nerve, a Berrettini's percentage was calculated [(amplitude digit III/amplitude digit IV) $\times 100$ ]. The normal peak latency of the SAP recorded at the fourth finger was established at $\leq 3.5 \mathrm{~ms}$. SAP belonging to Berretini's communication had similar peak latencies to those obtained in the fourth finger, in addition to a good configuration. Electrophysiological studies were performed with Dantec Keypoint equipment, version 2.40.0.263.

\section{Statistical Analysis}

A descriptive statistical analysis of the following variables was performed: gender, left or right handedness, and the Berretini percentage.

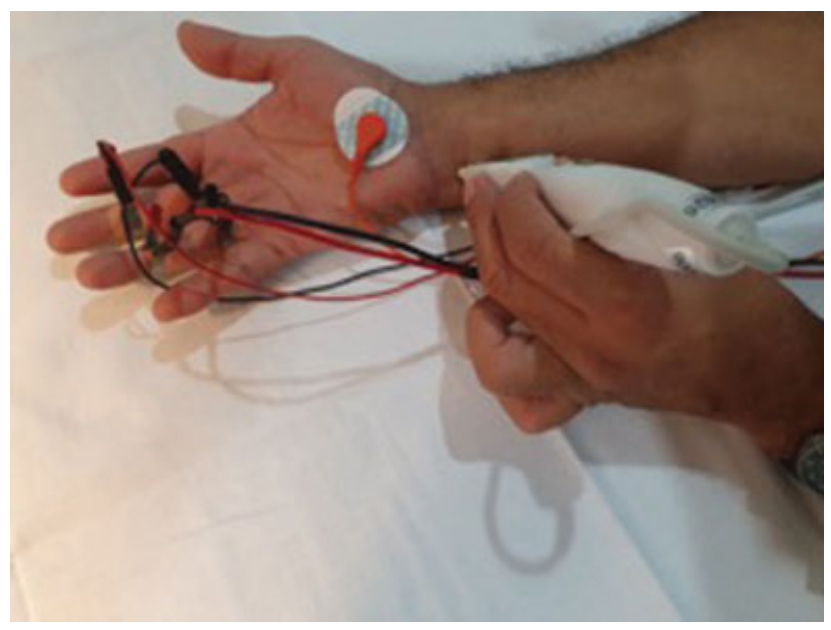

Fig. 1 Arrangement of the recording electrodes and the stimulator for the investigation of the Berrettini's connection.

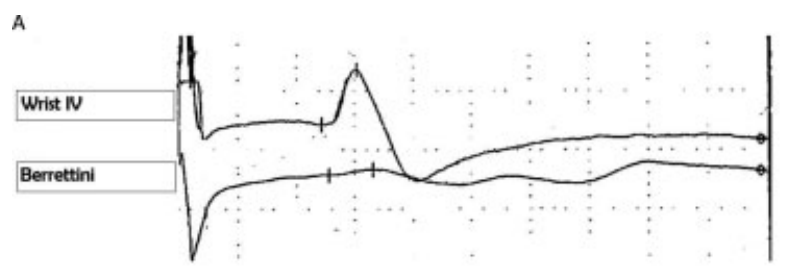

B

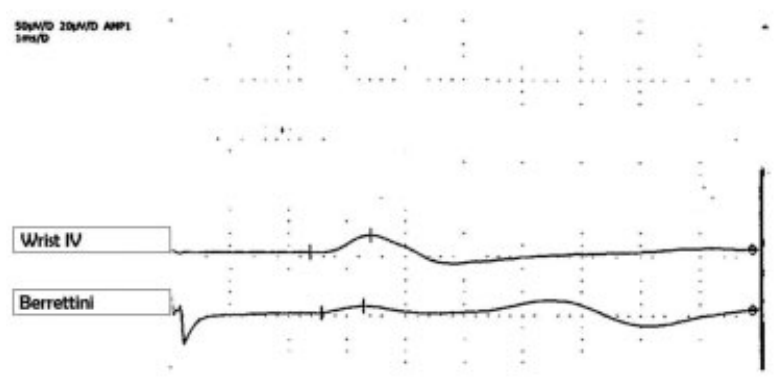

C

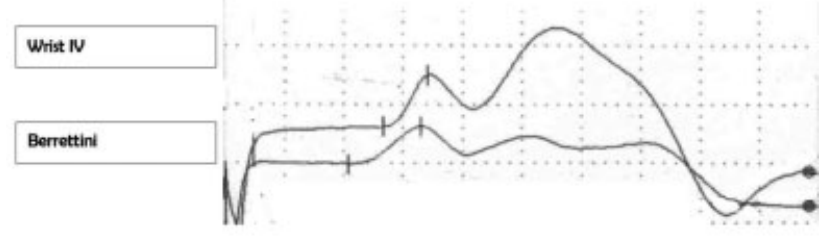

D

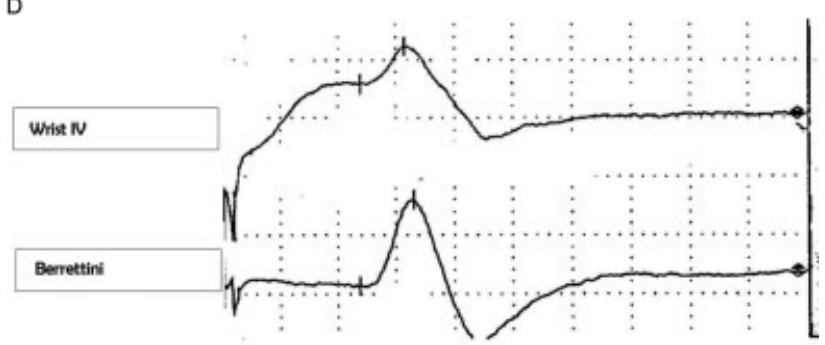

Fig. 2 Sensory nerve action potentials (SNAP) of the fourth cutaneous ulnar nerve, and the Berrettini's communication. (A) SNAP amplitude of Berrettini's communication (SAB) is $1.53 \mu \mathrm{V}$, SNAP amplitude of fourth cutaneous ulnar nerve (SA4) is $19.4 \mu \mathrm{V}$, and Berrettini's percentage (BP) is 7.88\%; (B) SAB is $5.8 \mu \mathrm{V}$, SA4 is $14.4 \mu \mathrm{V}$, and $B P$ is $40.27 \%$; (C), SAB is $12.9 \mu \mathrm{V}$, SA 4 is $17.3 \mu \mathrm{V}$, and $B P$ is $72 \%$; (D), $\mathrm{SAB}$ is $72.9 \mu \mathrm{V}$, SA4 is $33.6 \mu \mathrm{V}$, and $\mathrm{BP}$ is $216 \%$.

The present work followed the World Health Organization (WHO) Ethical Code (Helsinki's Declaration), and the Habeas Data Law. All the participants signed an informed consent, and the local Ethics Committee approved the research work.

\section{Results}

Three hundred and thirty-eight hands belonging to 169 patients with a median age of 58 years (age range: $18-85$ years) were studied.

The presence of a SAP corresponding to the Berrettini communication (10.95\%) was demonstrated in 37 hands in the sample studied: 34 patients (20.9\%) were shown to have this connection. Twenty-seven patients were female (79.41\%). In three women (1.78\%), this connection was found 
Table 1 Berrettini's percentage in four groups

\begin{tabular}{|l|l|}
\hline Berrettini's percentage & $\boldsymbol{n}(\%)$ \\
\hline $1-10 \%$ & $11(29.73)$ \\
\hline $11-50 \%$ & $17(45.95)$ \\
\hline $51-100 \%$ & $5(13.51)$ \\
\hline$>100 \%$ & $4(10.81)$ \\
\hline
\end{tabular}

bilaterally. Eighteen unilateral Berrettini's communications were found in left hands (53\%).

When considering the Berrettini ratio, four groups were found ( - Table 1 ): the highest percentage corresponded to 11 to $50 \%$.

\section{Discussion}

In the present work, the frequency of Berrettini's communication's electrophysiological finding was $10.95 \%$ which would imply a prevalence of $20 \%$. The prevalence was higher in women. In a low percentage, the presence of this connection was bilateral.

This frequency is lower than that reported by the work performed at Wayner State University, Michigan, which was evaluated from $33.9 \%$ of the patients. ${ }^{7}$ The explanation for this difference in frequencies could not be found with the data obtained and analyzed. In both studies, the low frequency of bilaterality is low, and the predominance in the female gender was found. However, the frequency of Berrettini's anastomosis encountered in the present study is slightly higher than the one reported in a study performed in Lima, Perú, which was $9.4 \%$ of the cases. ${ }^{1}$

Most Berrettini's communications encountered in this study had a Berrettini's percentage between 11 and $50 \%$. However, some connections had a Berrettini's percentage higher than $100 \%$. This finding was remarkable: these communications may probably have a greater number of axons than the fourth finger's cutaneous branch of the ulnar nerve. In a case series by Seidel et al, ulnar sensory nerve action potential (SNAP) amplitudes measured in the third finger were smaller than those measured in the fourth finger. ${ }^{8}$ In the study published in 2019, ulnar SNAP amplitudes measured in the fourth finger were $27 \%$ the size of those measured in the fourth finger. ${ }^{7}$

Pietro Berrettini da Cortona (1596-1669) was an architect and painter who illustrated the superficial palmar communication between the ulnar and median nerves in the Tabulae Anatomical atlas which was published in $1741 .{ }^{9}$ Meals and Calkins called it the Berrettini Anastomosis ${ }^{10}$; this consists of a communicating branch between the digital nerves coming from the median and ulnar nerves. The most common is that which, from the fourth common digital nerve, joins distally to the third digital nerve. ${ }^{11}$ Anatomical cadaveric studies showed a very high prevalence from 80 to $90 \%$, thus this connection might be a normal part of human anatomy. ${ }^{12-15} \mathrm{~A}$ meta-analysis showed that the prevalence is $60.9 \%$ in anatomical studies, with a high percentage of bilaterality
(60\%). ${ }^{16}$ The differences between these anatomical studies and the electrophysiological studies are likely due to the number of axons that contain the connections, some of them may have such a low number of axons that they would not be detected electrophysiologically.

There are several classifications of this connection, depending on the origin and the route. Ferrari and Gilbert ${ }^{18}$ classified it into four groups, Don Griot et $\mathrm{al}^{14}$ classified it into eight types, but the simplest is the classification by Meals and Shaner. ${ }^{12}$ The classification by Meals and Shaner classified it into three types as follows: type I, from the fourth common digital nerve (ulnar nerve), it is directed obliquely to the distal region of the third digital nerve (median nerve); type II, from the median nerve to the ulnar nerve; and type III, two communications, from the median nerve to the ulnar nerve and from the ulnar to the median. The most common is type I which has three subtypes as follows: IA in which the fibers are directed toward the radial side of the ring finger; $I B$, the fibers are directed to the radial side of the ring finger and the middle finger; and IC whose fibers reach the common digital nerve of the third finger, but the exact direction cannot be determined. ${ }^{11}$

It is essential to take this anatomical variant into account, since should it be injured iatrogenically during surgery for carpal tunnel syndrome or Dupuytren's contracture, the sequel may be an unpleasant tingling sensation in the radial half of the fourth finger and the ulnar half of the third finger. ${ }^{19}$ In addition to the electrophysiological evidence of Berrettini's anastomotic communication to the middle finger, ${ }^{1,7,8}$ a recent study has reported about Berrettini's anastomotic communication providing sensory supply to index finger too. ${ }^{20}$ Therefore, its routine electrophysiological search is recommended before surgery.

Conflict of Interest

None declared.

\section{References}

1 Lalo Velasquez JC, Barreto Montalvo J, Atoche Jasavi DR. Conexiones entre los nervios mediano-cubital por electromiografía en Lima (Perú), 2016. Rev Esp Cir Ortop Traumatol 2018;62(06): 415-420

2 Kretschmer T, Heinen CW, Antoniadis G, Richter HP, König RW. Iatrogenic nerve injuries. Neurosurg Clin N Am 2009;20(01): 73-90, vii

3 Kretschmer T, Heinen C. Iatrogenic injuries of the nerves. In: Tubbs RS, Rizk E, Shoja MM, Loukas M, Barbaro N, Spinner RJ, eds. Nerves and Nerve Injuries, Vol 2. Pain, Treatment, Injury, Disease and Future Directions. London, United Kingdom: Elsevier; 2015: 557-585

4 Stancić MF, Mićović V, Potocnjak M. The anatomy of the Berrettini branch: implications for carpal tunnel release. J Neurosurg 1999; 91(06):1027-1030

5 Boughton O, Adds PJ, Jayasinghe JA. The potential complications of open carpal tunnel release surgery to the ulnar neurovascular bundle and its branches: A cadaveric study. Clin Anat 2010;23 (05):545-551

6 Uchiyama S, Yasutomi T, Fukuzawa T, Nakagawa H, Kamimura M, Miyasaka T. Median nerve damage during two-portal endoscopic carpal tunnel release. Clin Neurophysiol 2004; 115(01):59-63 
7 Seidel G, Seidler M, Hakopian D, et al. Frequency of electrodiagnostically measurable Berrettini anastomosis. J Clin Neurophysiol 2019; 37(03):214-219

8 Seidel ME, Seidel GK, Hakopian D, Hornbach E, Andary M. Electrodiagnostic Evidence of Berrettini Anastomosis. J Clin Neurophysiol 2018;35(02):133-137

9 Choulant L. History and Bibliography of anatomic Illustration in Relation to Anatomic Science and the Graphic Arts. Chicago, IL: The University of Chicago Press; 1917:235-239

10 Smith JL, Siddiqui SA, Ebraheim NA. Comprehensive summary of anastomoses between the median and ulnar nerves in the forearm and hand. J Hand Microsurg 2019;11(01):1-5

11 Meals R, Calkins ER. Anomalous innervation of the upper extremity in operative repair and reconstruction. Lippincott, PA: JB Lippincott; 1991:197-204

12 Meals RA, Shaner M. Variations in digital sensory patterns: a study of the ulnar nerve-median nerve palmar communicating branch. J Hand Surg Am 1983;8(04):411-414

13 Kolic Z, Mikovic V, Zamolo G, Golubovic V, Uravic M, Stancic M. The anatomy of the Berrettini Branch: implications for endoscopic carpal tunnel release. Neurosurg Focus 1999;91(06):1027-1030
14 Don Griot JP, Zuidam JM, van Kooten EO, Prosé LP, Hage JJ. Anatomic study of the ramus communicans between the ulnar and median nerves. J Hand Surg Am 2000;25(05):948-954

15 Loukas M, Abel N, Tubbs RS, Matusz P, Zurada A, Cohen-Gadol AA. Neural interconnections between the nerves of the upper limb and surgical implications. J Neurosurg 2011;114(01):225-235

16 Roy J, Henry BM, PĘkala PA, et al. Median and ulnar nerve anastomoses in the upper limb: a meta-analysis. Muscle Nerve 2016;54(01):36-47

17 Ferrari GP, Gilbert A. The superficial anastomosis on the palm of the hand between the ulnar and median nerves. J Hand Surg $[\mathrm{Br}]$ 1991;16(05):511-514

18 Don Griot JP, Van Kooten EO, Zuidam JM, Prosé LP, Hage JJ. Internal anatomy of the communicating branch between the ulnar and median nerves in the hand and its relevance to volar digital sensibility. J Hand Surg Am 2002;27(01):143-146

19 Bozkurt MC. Berrettini branch. J Neurosurg 2011;114(01):276, author reply 276

20 Wakode SL, Ravi N, Agrawal A. Electrodiagnostic description of a rare variant of Berrettini anastomois: a case report. Int J Surg Case Rep 2020;76:404-408 